\title{
Emerging Thoughts on an Approach to Engaging Pupils in Effective Group Talk in Science
}

\author{
Abstract \\ Group talk opportunities in science can be a rich site for conceptual change. The role of the \\ teacher is vital in scaffolding the exploratory talk which can lead children to talk their way to \\ new understandings and clarify their ideas with peers. This study aims to uncover teacher \\ strategies which lead to effective talk for developing scientific understanding. The findings of \\ this small scale ethnographic case study suggest that the temporal organisation, the way in \\ which the teacher organises the timing of group discussion activities, may have an impact \\ upon the nature of the pupils' dialogue.
}

Keywords: exploratory talk; science; peer group talk; reflective practice; scaffolding

\section{Introduction}

This paper presents the findings from an exploratory small scale research study, the stimulus for which was my prior professional practice as a primary school teacher with a special interest in science. Greater use of speaking and listening techniques in the science classroom provided me with interesting ways to develop children's understandings but I identified a difficulty - providing time for pupil discussion was not enough to enable quality learning talk in my science classes. More of a framework for dialogue was required in order to allow children to talk around the planned learning intentions but also in desirable, exploratory ways.

Primary teachers face varying challenges in their efforts to both enthuse and engage pupils in science and guidance on how it is effectively and efficiently done is valuable. Teachers are encouraged to engage pupils in more talk in the classroom but specific advice on how this can be successfully achieved is sparse. The purpose of an overarching long term 
project, of which the study presented here is just the first phase, is to uncover how teachers engage pupils in effective group talk, which develops their scientific understanding. It hopes to gain understandings of teachers' practice and present potentially transferable strategies concerning the use of peer group talk in the primary science classroom. The initial small scale study reported here tested a particular methodology specifically developed for studying such group talk in science. This methodology places value on the class teacher's professional knowledge, understanding and skill and it incorporates observations of both teaching and learning but also a reflective conversation which engaged the practitioner in a focussed discussion about the use of talk in observed sessions.

Within this paper, both this methodology and some background to the use of group talk in science will be presented. It will also show that there is a gap, identified in the literature, in the way in which peer group talk has previously been analysed and it will discuss how this and conclusions from the small-scale study provide a way forward for developing my research.

\section{Theoretical Background}

\section{A socio-cultural perspective}

When viewed through a socio-cultural lens, human cognition is fundamentally a social process, mediated by the use of cultural tools such as language. The pupil is not seen to simply acquire knowledge but is a subjective learner, who arrives with past experiences and prior understandings and attempts active construction of reality, by making sense of experiences and reshaping understandings to gain a new perspective on the world. When pupils collaborate, they can be seen to construct their understandings socially, through discussion, explanation and justification of ideas; their joint activity and social interaction promotes intellectual development (Vygotsky 1986). This approach to working with pupils, 
where we see them as active agents, taking responsibility for their own learning and where that learning is situated in the context of collaborative work, is based upon the theory of social constructivism. It is based upon the Vygotskian principle that a child learns when guided to higher levels of cognitive development by talk and experience shared with adults and other more able peers. In this view of learning and development, a key role is clearly placed with language. Vygotsky analysed the social origins of cognitive developmental processes and saw children as able to socially construct knowledge and meanings of their world. Vygotsky prioritised 'intermental' functioning, mental processes occurring between people, for example dyads or small groups and viewed individual or 'intramental' mental processes as only emerging through the mastery of social processes. This emphasis upon the 'socially shared', leads to the assumption that cognition can be a function of social action. Discourse and joint action builds up a body of common knowledge (Edwards\& Mercer 1987) upon which further understandings can be constructed; exposure to the thinking of others helps individuals to reflect upon and evaluate their own understandings as they create shared knowledge with others (Gauvain, 1995). Teaching and learning can be seen as instruction for construction.

Each classroom in which teachers teach and pupils learn can be seen as a unique culture, coconstructed by teachers and pupils, creating an environment for education which is shaped by shared beliefs, rules and activities (Staub, 2007). Clearly, the teacher has a vital role to play not only in designing and facilitating the group discussion activities themselves but also in shaping the classroom culture so that talk engages and extends the pupils to achieve levels of understanding that they could not achieve independently. A study, such as this which takes a socio-cultural perspective must ensure that it takes account of the actions, words and thoughts of both pupils and teachers as they work together to build new understandings. 


\section{Constructing understanding in groups}

Through the constructivist approach that is now embedded in science teaching, children are seen as active learners, they build up new knowledge by modifying what they already know. They develop new ideas about their world based on observations and experiences, which sometimes challenge their existing ideas (Pelech\& Pieper 2010). This approach allows children to test out their emerging understandings, reflect upon them and prove them. Ideas can be internalised or alternatively put aside, any new understandings becoming the knowledge to now be acted upon and used. Children generate their own understanding of scientific concepts and the teacher's role is one of facilitating developing understanding by providing appropriate experiences (Gunstone 1995).

Clearly, one such experience could be the use of group discussion activities where pupils are enabled to specifically develop scientific understanding by communicating their ideas; peers talking with one another helps them to work on understanding (Barnes 1992). Group collaboration and discussion is a dynamic, creative and interactive context for science learning, popular with teachers and children (Murphy\& Beggs 2005; Howe et al. 2007) and pupil-pupil interaction has been found to be a productive forum for achieving conceptual change in science (Howe et al. 2000; Baines, Blatchford \& Chowne 2007; Thurston et al. 2010; Howe\& Tolmie 2003). During pupil-pupil interaction, the control is handed to the children and they are seen to co-construct knowledge; here, responsibility is shifted towards pupils and group talk is therefore an important pedagogical tool.

\section{Challenges of using group talk as a tool}

'Talk is arguably the true foundation of learning' (Alexander 2008, 9) 
This statement makes the claim for high levels of quality oral interaction in the classroom. The importance of talk has been increasingly highlighted in the last 35 years, beginning with the acknowledgement that children learn through talk in the Bullock Report (Bullock\& Department of Education and Science, 1975). This acknowledgement, led to studies which observed and analysed talk and classroom communication to reveal the learning and developmental processes occurring (Barnes, 1976; Barnes, 1977; Wells, 1987; Edwards\& Mercer, 1987; Cazden, 1988). In addition, the work of the National Oracy Project(Norman, 1992), which aimed to prioritise the role of talk in the learning process by enhancing teacher's practice and both the National Curriculum (1988) and Primary National Strategy (2003), where speaking and listening are given a high priority, have led to significant improvements in teacher knowledge and understanding of the importance of quality dialogue.

There has been much research on classroom talk, in the context of both teacher-pupil interactions and peer groups. In these two contexts for dialogue, the role of the teacher is paramount in engaging and extending the pupil to achieve levels of understanding that they could not achieve on their own:

- Teacher-pupil interaction - the expert guides and scaffolds the cognitive development of the learner, in order that they achieve common knowledge (Edwards\& Mercer, 1987). This idea of a guided construction of knowledge(Mercer, 1995) has led to the emerging pedagogy of dialogic teaching - using the power of talk to shape children's thinking, teaching which is collective, reciprocal, supportive, cumulative and purposeful (Alexander, 2008).

- Pupil-pupil interaction, where pupils co-construct knowledge in pairs or groups (Rogoff, 1998; Forman\& Cazden, 1985b). This joint venture, with no expert present to lead, hands control over learning to the children; the responsibility is shifted towards them but also it requires the development of social and communication skills(Thurston et al., 2010; Baines et al., 2009). Dialogic talk can be encouraged in this context too, for example, in the use of open ended questions to support such interaction between pupils (McNeill\& Pimentel, 2010).

There have been significant improvements in teacher knowledge and understanding of the importance of quality dialogue. It has been found that science learning can be more effective when teachers assign roles to children in the group, (Herrenkohl et al., 1999; Maloney, 
2007;Richmond\& Striley, 1996) or where teachers are specifically trained in group talk interventions that encourage and enable rather than stifle and constrain learning through talk(Baines et al., 2007). Some have found unsupported group discussion to be successful where children are specifically making sense of evidence (Lubben et al., 2010; Hogan, 1999).

Douglas Barnes (Barnes 1992) in his discussion on the value of talk for learning characterises speech as having two functions in the classroom: speech as communication and speech as reflection. The reflective process involves learners in sorting out their ideas, organising and clarifying with others, going back over an experience and representing it to themselves. The process leads to learners having to make their ideas explicit and clear through explanations. He stresses that while both forms of using speech are clearly vital in the classroom, unless there is a focus on reflective talk, children do not have the opportunity to work on their understanding. He also made the distinction between presentational talk and exploratory talk (Barnes 1992), the latter being the talk that is heard as children test out ideas. It is often hesitant and incomplete but it is the talk through which pupils manipulate ideas and construct meaning from them. This 'exploratory' category is also used, with two others, 'disputational' and 'cumulative', in the analysis of classroom talk (Mercer 1995). It is this exploratory type of talk that should be encouraged, even required, in order that children construct new understandings (Mercer 2004a), it is this type of talk that has been found more in small groups than in whole class situations (Meyer\& Woodruff 1997) and the study presented here uses the emergence of this type of talk during group work as the indicator of a productive discussion.

Clearly, talk between peers is of real significance in the classroom if we can get it right; planning for tasks where exploratory talk is supported, enables the potential for learning from talk to be exploited (Alexander 2008). In the teaching of science, talk opportunities provide 
the pedagogic means, the vehicles by which children develop their conceptual understanding (Millar\& Driver 1987); through talk the scientific story is introduced (Scott\& Ametller 2007). But teachers have few strategies at their disposal to maximise the power of talk, despite their enthusiasm (Mercer, Dawes \& Staarman Kleine 2009). In addition, there are such pressures on time for quality talk in classrooms that teachers need a developing pedagogical repertoire for improving it (Braund 2009). It has been suggested that research is needed on how science teachers may scaffold and organise group work, encourage reflection and monitor and guide group interactions (Baines, Blatchford \& Chowne 2007; Bennett et al. 2010; Howe et al. 2007). It has been suggested that when planning for and enabling group discussion the teacher faces a dilemma (Cohen 1994) - too much structured interaction in groups can prevent higher order thinking skills and formats can make the talk itself the centre of learning, leading thinking away from the scientific ideas (Keogh\& Naylor 2007). However, not enough structure may lead to a concrete mode of interaction and dialogic talk will not take place within the group.

In addition, there is a particular challenge in science; this can be thought of as, 'how can teachers teach the conceptual knowledge while still allowing their pupils the freedom to become scientific investigators and scientifically literate citizens?' Balancing the differing learning aims of the teaching of the prescribed scientific concepts and also the development of scientific inquiry and communication skills is a fundamental challenge for the science teacher wishing to engage children in peer group discussion (Ovens 2002). It is this problem that my study aims to address by looking closely for precisely which effective classroom practices and teacher roles lead to productive, exploratory group talk, where pupils act as inquirers with developing scientific understandings. 


\section{The role of the teacher in scaffolding understanding}

In teaching, the role of the adult is to 'scaffold' learning, to provide guidance and lend a structure to the tasks and activities (Bruner 1985) so pupils are exposed to increasingly complex understandings and activities. Scaffolding is help given that reduces the scope for failure (Maybin, Mercer \& Stierer 1992); the term 'scaffolding' has also been used to describe the way teachers support pupils without taking over responsibility for the learning (Mercer\& Fisher 1992).

The emphasis on the active role of the teacher has implications for viewing the teaching and learning using peer group collaboration through a Vygotskian socio-cultural perspective. It cannot be presumed that pupils grouped together without a teacher present will be enabled to learn; not all joint interactions lead to cognitive gain, due to social and communicative differences with the participants (Light\& Littleton 1994).

However, even though the teacher may not be there to mediate the group discussion with their own talk, teacher 'scaffolding' of peer group interactions must still be seen as an important construct in developing children's understandings in science in this context. It can be viewed as more than the way teachers question and feedback in dialogic interactions. The role of the teacher is vital in setting learning intentions and outcomes, in setting up the group environment (Maybin, Mercer \& Stierer 1992) and in designing the task (Howe\& Tolmie 2003; Tolmie et al. 1993). This study therefore focusses on what teachers do and more specifically how they manage the timing of discussion, both within and between sessions - a temporal approach. I hoped through studying the varying ways in which teachers successfully scaffold group discussion in science I would uncover strategies which other practitioners could transfer to their own socio-cultural context. 


\section{Research Methodology}

For this study the assumption has been made that the reality of the studied classroom, its members and small groups, is a unique culture; a social construction with multi layers of interaction and multiple perspectives on any single event; an environment created for education and shaped by shared beliefs, rules and activities (Staub 2007). This reality is built by the creative, individual people who inhabit it and interact within it. Knowing about the multi-perspectives within the classroom can only be found through discussion with participants and by seeking to gain an appreciation of their viewpoints and reasons for action; observation alone is not enough. This case study therefore took ethnography as an overarching methodological backdrop. The ethnographer's job is to 'go native'; to create thick descriptions of a culture and to share the meanings of participants (Bogdan\& Biklen 2003). This research tradition involves participant observation and a great deal of time is given to knowing the world of each classroom under study. Although written accounts of what is heard and observed are subjectively written, the culture and context under study can be vicariously experienced by outsiders and new understandings can be represented.

\section{Context of the Study}

The study was set in a mainstream urban school with a socially mixed catchment area and a wide ability range of pupils. For the purpose of testing the chosen methodology, one school and one teacher were chosen. The class was Year 4 with 31 pupils, 6 of which were children with EAL. Year 4 was chosen because children of this age are mature enough to be able to work collaboratively in groups, keeping focussed on a common aim. They have had exposure to the way in which school science works, but have not yet become disillusioned(Beggs\& Murphy 2001), have been in school long enough to have developed knowledge of the implicit ground-rules of classroom interaction and have awareness that educational discourse is a 
process which embodies questions and both builds and checks understandings. The teacher was an experienced Key Stage 2 practitioner, had previously been science coordinator and had attended a round of 'talk for learning' courses laid on by the local authority. These factors were all important in choosing this particular teacher-partner, as the study wished to presume a particular interest in science teaching and an understanding of the importance of dialogue for learning. In addition, a practitioner who is experienced is more likely to feel secure in being recorded and observed.

\section{Classroom Data Collection}

The empirical research focussed on exploring and observing small group dialogue in science and the teaching input which led to it. In the classroom, observational notes were made on the nature of the group work, learning intentions, teacher input and activities set. A format of semi-structured written commentary was developed for the group work tasks and session as a whole, focussing on teacher input. Subsequently, a detailed summary of the lesson was created using any observation notes and commentary.

Audio recordings were made of a single group during the discussion time within science sessions. The group was not removed from the classroom as a natural situation was important to the study. Initially, recordings were only made of the group talk, however, in later sessions the recorder was left on for the whole lesson. Not only did this seem to reduce the effect of the recorder being present, as nobody was interrupting the flow to switch it on and off, but it also allowed for a review of the teacher talk which occurred before and after group sessions. The group talk was transcribed and Graddol's parallel column format (Edwards\& Westgate 1994)was chosen specifically for its ability to show overlap and cumulation in a graphic way. 
After each science session the children were interviewed to gain an understanding of their ideas about the relevance and role of talk in their new science learning. The questions were designed to find out what they valued most in group dialogue and how they felt it had been most successful in helping them to learn.

\section{Teacher Reflection through an Oral Diary}

After each session, the teacher was asked to reflect upon the lesson and it was hoped that it would stimulate regular and focussed action upon peer group talk. Much of the literature on reflective practice discusses the use of diaries or reflective learning journals (Moon 1999; Bolton 2001) but I did not wish to require the teacher to write lengthy reflections as a part of this study, as I was conscious of a teacher's busy schedule. An interview type format with questions based upon a reflective cycle was designed in order to capture immediate teacher impressions on the learning taking place through talk opportunities; it was intended to also be a platform for further reflection before the next session. The framework for reflection (Scaife 2010) was based on Kolb's cycle of experiential learning. A ten minute time limit was put on the discussion, so that it did not impact too heavily on the myriad of after school teacher tasks. This structured discussion was recorded and a written summary was created. Both this and the transcription of group talk were sent to the class teacher, within days. This served two functions: the documented teacher impressions could be confirmed as a correct representation and they could both be used alongside a more formal written reflective diary which was provided if the teacher so wished.

Finally, after all the observations and reflections, which occurred over a period of four weeks, the teacher was interviewed to find out if the project had had an effect upon their awareness or use of group talk, what strategies had been particularly successful, their feelings about the reflective cycle and about the project as a whole. 


\section{Methods of Analysis}

The children's talk was subject to analysis, of which there are many kinds, all with distinguishing features. Conversation analysis focuses on turn taking, sequences, fragments of utterances and other minute features of language in interaction (Cole\& Zuengler 2008), involves a micro-analysis of recurring patterns of talk and views talk as language in interaction (Wooffitt 2005), whereas discourse analysis views talk as language in use (Rex\& Schiller 2009). So, for the group talk, a method of Sociocultural Discourse Analysis was used (Mercer 2004b) which was chosen for its concern with both learning outcomes and processes of joint engagement and its ability to track the development of common knowledge across time. The analysis of the talk proceeded at a range of levels (Mercer 1995); a linguistic level and at a psychological and cultural level which together provide a commentary upon the thoughts and actions of the pupils and how much they entered into an 'educated' discourse (Mercer 1995). A further layer was added to the analysis, one which used the observation and interview data collected to look at teacher action and its impact upon the talk.

The talk data gathered, was transcribed. The transcribed talk was analysed for the features of exploratory talk that it displayed (Mercer\& Hodgkinson 2008; Barnes 1992), using the following criteria:

Table 1 here - Features of productive talk

The total number of each feature was calculated and this was seen to be an indication of how successful the session was at creating conditions for purposeful talk for learning. Particularly successful or unsuccessful sessions were then analysed for possible teacher action which led to it. 


\section{Ethical Considerations}

This study took place in a school where I had recently worked as a teacher and so gaining access and building relationships was a relatively smooth and easy process. Having some prior understanding of the context was very useful but in fact, it also meant that I encountered some difficulties. In this familiar environment it was tricky to move into the new role of researcher, however, the children seemed to accept it. I also had some concerns over the way in which the teacher may view me. Perhaps as an ex-colleague, some obligation was felt to be part of the study, perhaps it was awkward to be observed by someone known quite closely in a different capacity. This ethical issue was dealt with by giving the teacher an information leaflet before the project began and sharing emerging thoughts and reflections as the study progressed. Perhaps this level of honesty went someway to making us both at ease with the new working situation. In addition, I was most careful to express my wish not to take too much teacher time up and to emphasise how the study had been designed to minimise this.

\section{Analysis and Findings}

For the purposes of this study, all of the data types were initially explored and coded to discover themes that arose regularly for the teacher and pupils. A number of issues were then identified as having an impact upon the quality of talk in the groups:

- Groupings of children

- Resources available

- Teacher scaffolding understanding through time

- Type of teacher questioning

- Security of environment for talk

- Prior understandings of pupils 
- Teacher's knowledge of what the groups had discussed

- Timing of talk sessions

- Children's roles within the groups

It was decided to focus more in-depth analysis upon one of these categories - teacher scaffolding understanding through time - both because a lot of research has looked at some of the other areas, such as roles, questioning and groupings but also because during the children's interviews, the way the teacher organised the 'building up of ideas' within and between lessons, emerged as important for them.

During these interviews, when asked what they thought were useful ways in which the teacher organised discussion work, pupils mentioned the importance of working in groups: 'In small groups you get more of a chance to talk though, it gives you confidence because you may have an idea you are too worried to share with the class or you are not sure about it and someone else can say you are right and it helps you'

'More people then add their ideas and maybe give some other ideas'

'You can build up ideas and get even more in a group and even steal people's ideas.' However, pupils also valued the way in which their teacher used the whole class discussion because:

'Other people in the class have ideas you have never thought of' 'You can listen to things you did not know and then think about it and talk about it'.

It became clear that pupils felt it was useful when the teacher gave time to bring small group discussions together at points within the lesson, so ideas could be clarified in the whole class forum:

'This is good for really hard questions because they (the teacher) put all the ideas together' 
'You can build up on the ideas until you get a really scientific answer. You can do this in a small group but it takes longer and it's not always as good an answer, you may not get to the end of it.'

Some other pupils also talked in a different way about their teacher providing this time after group discussion to report back on any new ideas. Some responses about the importance of this for pupils included 'putting ideas into your own words', 'being the teacher' and 'saying it in a different way for other groups'.

When asked about teachers discussing ideas as a class before group work, some pupils said that it helped:

'Next time when you talk, you might understand it more and find your own way around it more' and 'You can mix it up with your own ideas and put it your own way'.

Clearly the pupils in this study found a mix of group and class discussion opportunities important. The way in which their teacher shaped and timed sessions to include both of these forums has begun to emerge, in this context, as a potential factor in how well these pupils see that they are able to learn in science sessions.

The following particularly successful group discussion has been analysed for the possible teaching strategies which may have preceded it. This extract is from of a transcript of lesson on the function of roots:

The lesson follows sessions on seeds and healthy growth of plants, including planting out for a new garden area. The lesson began with a whole class discussion on the parts of a plant and a group discussion which elicited various functions of roots that were then reported back to the class. The teacher displayed a number of plants with complex root systems and asked the children to discuss why the plants have so many roots. After two minutes, the teacher asked the group to stop the discussion and report back to the class. 
Table 2 here- Transcript of group talk

Despite the short amount of time that the children were given to discuss the question, a good amount of exploratory talk occurred, which is clear from the table above. In fact this slot of talk had the only hypothetical question observed over the study period. The children were engaged in the talk task from the outset, used a lot of physical gesture to describe their ideas, leaning into one another to talk and in the absence of anything nearby to draw on, they used pencil cases to physically model their ideas about keeping plants upright! The discussion was lively, relevant and focussed on the task but by the end the group were unable to come to a consensus. Perhaps they did not really have enough time to resolve their conceptual conflict as they were only given two minutes for the discussion and therefore in this way it could be seen as an unsuccessful episode; the teacher had set the task as one from which they were to report ideas back to the class and this implies that some consensus was in fact expected from the group, however, was not achieved.

The children's discussion began with Robert making a reference to some knowledge he held. This was quickly challenged by Clare, and Grace and Lisa almost simultaneously began to air their ideas of how the plant is structured, in perhaps in some way clarifying their initial thinking. Simon entered the discussion contributing his understandings of root systems but again Clare challenged. In previous sessions, Clare had evolved as group leader, almost gatekeeper; ideas were mediated through her as other group members referenced comments to her specifically. This dominant person, who in this episode was making all the challenges, was unable to agree with the half-formed ideas emerging. Her first three contributions were challenges to the thread of the discussion and at first this seems to block progress to a consensus but in fact her input pushes for clarifications and leads to a justification from 
Robert, with subsequent reformulations from Lisa and Simon as they begin to align themselves with his way of thinking that more leaves must mean more roots. In fact, their vocabulary is different, perhaps showing that they are extending the idea, proposing a relationship between stems and roots. Robert seemed rather pleased with himself at this point with his 'I told you' as the group seemed to be moving with his ideas until Clare injects an interesting question - 'What if you had one stem?'. This clearly prompted the group to rethink and Robert began to elaborate his thinking to take account of this challenge. He was joined by Grace and the discussion appeared to enter a new phase until it was cut short by the teacher at what was perhaps a crucial moment. It seems here that the timing allowed for this slot of talk had an impact on what could be realistically achieved by the children in terms of knowledge production. The open nature of the question meant that children were successfully engaged and focussed throughout. However, the nature of the question also meant that the children had to use their inquiry skills to hypothesise, a fairly high order requirement and so this discussion perhaps needed more time to gain momentum.

The children seem to have gone some way to expressing an idea and some elaboration was occurring but they did not have the time to tease this out further. The teacher asked for a group response and the dominant speaker offered his idea to the forum, despite the fact that it had not actually been agreed by the group. Despite the lack of consensus, there are many features of exploratory talk present and the pupils are fully engaged. The teacher's open question here, 'Why does a plant have so many roots?' clearly gave rise to much purposeful talk, even though there was actually very little time allowed for it. The talk evidenced assertion, challenge and justification; scientific inquiry and communication were in action, as children questioned and reasoned through their ideas. This perhaps led for some (Robert) to stronger understanding and others (Grace, Simon and Lisa) to half formed ideas requiring more time for development - perhaps also though to frustration for Clare as she did 
not have her questions answered. The difficulty here could be that the group as a whole have not come to an understanding, one pupil has begun to convince others of his view but any challenge had little time to gather support.

Before the group talk, the teacher had already elicited the functions of roots, reviewing a common knowledge upon which the children could build a new understanding and see a continuity of experience. The teacher spent time looking at examples of and describing complex root systems with the children as a whole class, which enabled them to have a concrete experience to base their talk upon. Through the oral diary data, it became clear that the teacher thought that this was an important issue. The phrasing and positioning of the questions within the session was reflected on as being important, in that they led into one another and children could follow through accepted ideas into the next discussion. Again, from oral diary interview data, it became apparent that this talk opportunity was in fact, not planned prior to the session but occurred in response to the unfolding and dynamic classroom situation and this may explain the short time given to the task within the lesson. In fact, the teacher felt that the idea of the function of roots had been grasped more quickly than she had anticipated, she felt that the children were sure of their ground and she wanted to extend their thinking by progressing the questioning and enable them to build upon their understanding and try out their ideas. This was, in terms of the type of talk exhibited, clearly a successful strategy, despite the fact that the children did not have enough time to gain consensus and also that Ben felt unable to participate. In this case, it could have been down to the fact that he had not grasped the preceding concepts strongly enough and could not therefore engage in this higher order talk or perhaps he just did not have time to develop and articulate his ideas. In either scenario, there are implications for teacher action, perhaps in terms of grouping or as this study suggests in planning timings. 
For the majority of the group, perhaps the success of this discussion was not only down to the nature of the question but also to its temporal situation within the lesson and the preceding scaffolding of ideas by the teacher, ensuring a secure foundation of knowledge on which the talk opportunity could build. It appears from this short piece of evidence that there may be some claims to be made concerning the importance in the way the teacher conceptually prepares the children for a group discussion, providing experience and reviewing their platform of understandings before allowing them independent talk time.

\section{Conclusion}

Group work has a positive effect in primary science teaching. Productive and exploratory classroom talk is a vital ingredient and a rich resource for successful learning in this context. But talk is not a panacea; successful talk needs to be embedded in a planned sequence of work, talk needs guidance and supervision, just allowing time for group discussion is not a solution (Barnes 2008). This teaching role in the guidance of construction of knowledge is key, when viewed through a socio-cultural perspective; even when they are not present in the group discussion, teachers have an impact which comes from their facilitating and scaffolding role, through the thinking over and planning of tasks and their dynamic reflection in action.

The findings from this small scale study obviously have implications for my own developing research but perhaps also for primary practitioners. The temporal organisation of group discussion activities within the session seems to have a bearing on the way in which children are enabled to engage in productive discussion. The way in which the teacher scaffolds and conceptually prepares the group appears important. In other words, what the teacher does before the group activity seems to have an impact on the productivity of the pupil talk which in turn feeds into pupils' learning and attainment. It was also clear from 
interviews with children that they felt that movement between whole class and group discussion opportunities enabled them to consolidate and clarify their learning. The teacher's consideration of the positioning or temporal organisation of group discussion opportunities within the whole class session also emerged from the oral diary data as an important issue. This perhaps may have had an impact on these children's attitudes to their science sessions as they were provided with experiences which they believed facilitated learning.

This data suggests that it is when thinking about, planning for and temporally structuring the peer discussion task and when balancing social, contextual and historical issues to enable exploratory talk to occur, where teachers can demonstrate their skill and deliver their expert guidance.

However, the findings of this study are based upon a relatively small amount of classroom data. It has been suggested that analysis of snapshots and one off conversations are limited and that by using a temporal analysis, one which takes place over a long period of time, it is possible to look at how joint construction of understanding occurs through time, as participants draw upon shared history (Mercer 2008). Therefore, I propose for my developing research, a temporal analysis of the way in which peer group dialogue is structured in science, both within and between sessions. Through this, I hope to identify the ways in which a teacher may think about and temporally scaffold pupils to new scientific understandings across time, through the use of productive group talk. This has potential benefits for practitioners, as it should uncover productive and transferable classroom strategies.

\section{References}

Alexander, R. 2008. Towards dialogic teaching. Fourth Edition ed. UK: Dialogis UK.

Baines, Ed, Peter Blatchford, and Anne Chowne. 2007. Improving the effectiveness of collaborative group work in primary schools: Effects on science attainment. British Educational Research Journal 33 (5): 663-80. 
Baines, E. Rubie,Davies,Christine,M. and Blatchford, P. 2009. Improving pupil group work interaction and dialogue in primary classrooms: results from a year-long intervention study. Cambridge Journal of Education. 39(1), 95-117.

Barnes, D. 1976. From Communication to Curriculum, Harmondsworth: Penguin Books.

Barnes, D. 1977. Communication and Learning in small groups. London: Routledge and Kegan Paul.

Barnes, Douglas. 1992. From communication to curriculum. Second Edition ed. Portsmouth, NH: Boynton/Cook.

Barnes, D. 2008. Exploratory talk for learning. In Exploring talk in school., eds. N. Mercer, S. Hodgkinson, 1-15. London: Sage.

Beggs, Jim, and Colette Murphy. 2001. Pupils attitudes, perceptions and understanding of primary science: Comparisons between northern Irish and English schools. : 18.

Bennett, Judith, Sylvia Hogarth, Fred Lubben, Bob Campbell, and Alison Robinson. 2010. Talking science: The research evidence on the use of small group discussions in science teaching. International Journal of Science Education 32 (1): 69-95.

Bogdan, R. C., and Sari Knopp Biklen. 2003. Qualitative research for education: An introduction to theory and methods. 4th ed. Boston: Allyn \& Bacon.

Bolton, G. 2001. Reflective practice: Writing and professional development. London: Paul Chapman.

Braund, M. 2009. Talk in primary science: A method to promote productive and contextualised group discourse. Education 3-13 37 (4): 385-97.

Bruner, J. 1985. Vygotsky: A historical and conceptual perspective. In Culture, communication and cognition: Vygotskian perspectives., ed. J. V. Wertsch, 21-34. Cambridge: Cambridge University Press.

Bullock, J. and Department of Education and Science, 1975. The Bullock Report: A language for life. London: Her Majesty's Stationery Office.

Cazden, C. 1988. Classroom Discourse: The language of teaching and learning. 1 st ed.

Portsmouth, N.H.: Heinemann.

Cohen, Elizabeth G. 1994. Restructuring the classroom: Conditions for productive small groups. Review of Educational Research 64 (1) (Spring): pp. 1-35.

Cole, K., and J. Zuengler, eds. 2008. The research process in classroom discourse analysis : Current perspectives. London: Lawrence Erlbaum Associates.

Edwards, A. D., and D. Westgate. 1994. Investigating classroom talk. Second Edition ed. London: The Falmer Press. 
Edwards, D., and N. Mercer. 1987. Common knowledge: The development of understanding in the classroom. London: Methuen.

Forman, E.A. and Cazden, C.B. 1985. Exploring Vygotskian Perspectives in Education: The cognitive value of peer interaction. in J. Wertsch (ed.) Culture, Communication and

Cognition: Vygotskian perspectives. Cambridge: Cambridge University Press, 323-347.

Gauvain, M. 1995. Thinking in Niches: Sociocultural influences on cognitive development, Human Development, 38(1): 25-45.

Gunstone, R. 1995. Learners in science education. In Development and dilemmas in science education., ed. P. J. Fensham. London: The Falmer Press.

Herrenkohl, L.R. Palinscar, A.S. Water, L.S. and Kawasaki, K. 1999. Developing Scientific Communities in Classrooms: A Sociocognitive Approach. The Journal of the Learning Sciences, 8(3/4), 451-493.

Hogan, K. 1999 Thinking aloud together: A test of an intervention to foster students' collaborative scientific reasoning. Journal of Research in Science Teaching, 36(10), $1085-$ 1109.

Howe, C., A. Tolmie, V. Duchak-Tanner, and C. Rattray. 2000. Hypothesis testing in science: Group consensus and the acquisition of conceptual and procedural knowledge Learning and Instruction 10 (4): 361-91.

Howe, Christine, and Andy Tolmie. 2003. Group work in primary school science: Discussion, consensus and guidance from experts. International Journal of Educational Research 39 (1-2): 51-72.

Howe, Christine,J., Andrew Tolmie, Allen Thurston, Keith Topping J., Donald Christie F.M., Kay Livingston, Emma Jessiman, and Caroline Donaldson. 2007. Group work in elementary science: Towards organisational principles for supporting pupil learning. Learning and Instruction 17 (5): 549-63.

Keogh, B., and S. Naylor. 2007. Talking and thinking in science. School Science Review 88 (324): 85-90.

Light, P., and K. Littleton. 1994. Cognitive approaches to group work. In Groups in schools., eds. P. Kutnick, C. Rogers. London: Cassell

Lubben, F. Sadeck, M. Scholtz, Z. and Braund, M. 2010. Gauging students untutored ability in argumentation about experimental data: a South African case study. International Journal of Science Education, 32(16), 2143-2166.

McNeill, K.L. and Pimentel, D.S. 2010. Scientific Discourse in Three Urban Classrooms: The role of the teacher in engaging high school students in argumentation. Science Education, 94(2), 203-229.

Maloney, J. 2007. Children's roles and use of evidence in science: an analysis of decisionmaking in small groups. British Educational Research Journal, 33(3), 371-401. 
Maybin, J., N. Mercer, and B. Stierer. 1992. 'Scaffolding' learning in the classroom. In Thinking voices: The work of the national oracy project., ed. K. Norman, 186-195. London: Hodder \& Stoughton.

Mercer,N. 1995. The guided construction of knowledge: Talk amongst teachers and learners. Clevedon: Multilingual Matters.

Mercer, Neil. 2004a. Reasoning as a scientist: Ways of helping children to use language to learn science. British Educational Research Journal 30 (3): 359-77.

Mercer, N. 2004b. Sociocultural discourse analysis: Analysing classroom talk as a social mode of thinking. Journal of Applied Linguistics 1 (2): 137-68.

Mercer, N. 2008. The seeds of time:Why classroom dialogue needs a temporal analysis. Journal of the Learning Sciences 17 (1): 33-59.

Mercer, N., and E. Fisher. 1992. How do teachers help children to learn? an analysis of teachers' interventions in computer-based activities. Learning and Instruction 2 : 339-55.

Mercer, Neil, and Steve Hodgkinson, eds. 2008. Exploring talk in schools : Inspired by the work of Douglas Barnes. London: Sage.

Mercer, Neil, Lyn Dawes, and Judith Staarman Kleine. 2009. Dialogic teaching in the primary science classroom. Language and Education 23 (4): 353-69.

Meyer, K., and E. Woodruff. 1997. Consensually driven explanation in science teaching. Science Education 81 (2) (APR): 173-92.

Millar, R., and R. Driver. 1987. Beyond processes. Studies in Science Education 14 : 33-62.

Moon, J. 1999. Learning journals: a handbook for academics, students and professional development. London: Kogan Press

Murphy, C., and J. Beggs. 2005. Primary science in the UK: A scoping study. Belfast: Wellcome Trust,.

Norman, K. (ed.) 1992. Thinking Voices: The work of the National Oracy Project, London: Hodder \& Stoughton.

Ovens, P. Evidence based teaching in primary school science : The Nottingham EBT project. 2002. Available from http://www.nfer.ac.uk/nfer/PRE PDF Files/02 28 07.pdf.

Pelech, J., and G. Pieper. 2010. The comprehensive handbook of constructivist teaching. Charlotte, NC: Information Age Publishing.

Rex, L. A., and Laura Schiller. 2009. Using discourse analysis to improve classroom interaction. New York; London: Routledge. 
Richmond, G. and Striley, J. 1996. Making Meaning in Classrooms: Social Processes in Small-Group Discourse and Scientific Knowledge Building. Journal of Research in Science Teaching, 33(8), 839-858.

Rogoff, B. 1998 Cognition as a collaborative process. in D. Kuhn and R. Siegler (eds.) Handbook of Child Psychology Volume 2: Cognition, perception and language. Chichester: John Wiley \& Sons, 679-744.

Scaife, J. 2010. Supervising the reflective practitioner: An essential guide to theory and practice. London: Routledge.

Scott, P., and J. Ametller. 2007. Teaching science the meaningful way. School Science Review 88 (324): 77-83.

Staub, Fritz,C. 2007. Mathematics classroom cultures: Methodological and theoretical issues. International Journal of Educational Research 46 (5): 319-26.

Thurston, A., Topping, K.J., Tolmie, A., Christie, D., Karagiannidou, E. and Murray, P. 2010. Cooperative Learning in Science:Follow-up from primary to high school, International Journal of Science Education 32(4): 501-522.

Tolmie, Andrew, Christine Howe, Mhairi Mackenzie, and Karen Greer. 1993. Task design as an influence on dialogue and learning: Primary school group work with object flotation. Social Development 2 (3): 183-201.

Wells, G. 1987. The Meaning Makers: Children Learning Language and Using Language to Learn. London: Hodder \& Stoughton.

Wooffitt, R. 2005. Conversation analysis and discourse analysis : A comparative and critical introduction. London: Sage.

Vygotsky, L. 1986. Thought and language. Cambridge, Mass: The MIT Press. 